\title{
Patient treatment and outcome after breast cancer orbital and periorbital metastases: a comprehensive case series including analysis of lobular versus ductal tumor histology
}

Martin Blohmer ${ }^{1,2,3}$, Li Zhu $^{4}$, Jennifer M. Atkinson ${ }^{1,3}$, Sushil Beriwal ${ }^{5}$, Joshua L. Rodríguez-López ${ }^{5}$, Margaret Rosenzweig ${ }^{3,6}$, Adam M. Brufsky ${ }^{7}$, George Tseng ${ }^{3,7}$, Peter C. Lucas ${ }^{3,8}$, Adrian V. Lee ${ }^{1,3 \dagger}$, Steffi Oesterreich ${ }^{1,3+}$ and Rachel C. Jankowitz ${ }^{7,9,10^{*}+}$

\begin{abstract}
Background: Breast cancer is the most common malignancy to spread to the orbit and periorbit, and the invasive lobular carcinoma (ILC) histologic subtype of breast cancer has been reported to form these ophthalmic metastases (OM) more frequently than invasive ductal carcinomas (IDC). We herein report our single academic institution experience with breast cancer OM with respect to anatomical presentation, histology (lobular vs. ductal), treatment, and survival.

Methods: We employed the natural language processing platform, TIES (Text Information Extraction System), to search 2.3 million de-identified patient pathology and radiology records at our institution in order to identify patients with OM secondary to breast cancer. We then compared the resultant cohort, the "OM cohort," to two other representative metastatic breast cancer patient (MBC) databases from our institution. Histological analysis of selected patients was performed.

\footnotetext{
* Correspondence: Rachel.Jankowitz@Pennmedicine.upenn.edu

${ }^{+}$Adrian V. Lee, Steffi Oesterreich, and Rachel C. Jankowitz shared senior authorship.

Martin Blohmer and Rachel C. Jankowitz completed their work at the University of Pittsburgh.

7University of Pittsburgh School of Medicine, Department of Medicine, Division of Hematology/Oncology, UPMC Hillman Cancer Center, Pittsburgh, PA, USA

${ }^{9}$ Department of Medicine, Division of Hematology/Oncology, Perelman School of Medicine, Abramson Cancer Center, University of Pennsylvania, Philadelphia, PA, USA

Full list of author information is available at the end of the article
}

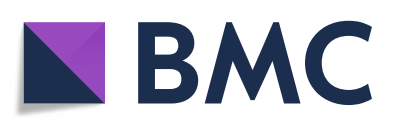

(- The Author(s). 2020 Open Access This article is licensed under a Creative Commons Attribution 4.0 International License, which permits use, sharing, adaptation, distribution and reproduction in any medium or format, as long as you give appropriate credit to the original author(s) and the source, provide a link to the Creative Commons licence, and indicate if changes were made. The images or other third party material in this article are included in the article's Creative Commons licence, unless indicated otherwise in a credit line to the material. If material is not included in the article's Creative Commons licence and your intended use is not permitted by statutory regulation or exceeds the permitted use, you will need to obtain permission directly from the copyright holder. To view a copy of this licence, visit http://creativecommons.org/licenses/by/4.0/. The Creative Commons Public Domain Dedication waiver (http://creativecommons.org/publicdomain/zero/1.0/) applies to the data made available in this article, unless otherwise stated in a credit line to the data. 
(Continued from previous page)

Results: Our TIES search and manual refinement ultimately identified 28 patients who were diagnosed with breast cancer between 1995 and 2016 that subsequently developed OM. Median age at diagnosis was 54 (range 28-77) years of age. ER, PR, and HER2 status from the 28 patients with OM did not differ from other patients with MBC from our institution. The relative proportion of patients with ILC was significantly higher in the OM cohort (32.1\%) than in other MBC patients in our institution (11.3\%, $p=0.007)$. Median time to first OM in the OM cohort was 46.7 months, and OM were the second most frequent first metastases after bony metastases. After diagnosis of the first distant metastasis of any kind, median survival of patients with ILC (21.4 months) was significantly shorter than that of patients with IDC (55.3 months, $p=0.03$ ). Nine patients developed bilateral OM. We observed a significant co-occurrence of OM and central nervous system metastases $(p=0.0053)$. The histological analysis revealed an interesting case in which the primary tumor was of a mixed ILC/IDC subtype, while only ILC was present in the OM.

Conclusions: OM from breast cancer are illustrative of the difference in metastatic behavior of ILC versus IDC and should be considered when treating patients with ILC, especially in those with complaints of visual acuity changes.

Keywords: Breast cancer, Invasive lobular carcinoma, Metastasis, Eye, Ophthalmology

\section{Background}

With over 1.5 million new cases each year, breast cancer accounts for $25 \%$ of all cancer cases in women worldwide [1]. Breast cancer is a heterogenous disease, both molecularly and histologically. The invasive lobular carcinoma (ILC) histologic subtype represents $10-15 \%$ of all breast cancer, constituting the second most common subtype after invasive ductal carcinoma (IDC) [2].

ILC is marked by its characteristic loss of the cell adhesion molecule E-cadherin. In classical ILC, invasive cells grow in single file pattern with little disruption of the stroma [3]. ILC is also commonly characterized by pathological features that are usually associated with a good prognosis, such as hormone receptor (HR) positivity, human epidermal growth factor receptor (HER2/neu) negativity, low proliferative rate, and low histological grade [4], yet it has been described to have a higher propensity for late distant metastases compared to IDC tumors of similar grade and hormone receptor status $[5,6]$.

The relevance of differentiating outcome in patients with ILC versus IDC histological subtypes stems from their reported unique clinical presentations, including their sites of metastases, survival rates, and responses to systemic therapy. While few studies directly compare therapeutic response in patients with ILC vs. IDC, response to neoadjuvant chemotherapy has been reported to be lower in patients with ILC compared to patients with IDC [7], and the proportional advantage of adjuvant aromatase inhibitors over tamoxifen is reported to be higher for patients with ILC compared to patients with IDC [8]. Moreover, patients with ILC have a 50\% higher risk of death after 10 years in comparison to patients with IDC [9]. Finally, we and others have shown unique patterns of metastases for patients with ILC, with ILC more likely to metastasize to the ovaries and gastrointestinal tract, and IDC more likely to metastasize to the lung and the liver [10-12].
Ophthalmic metastases (OM) are rare and often caused by carcinomas like breast cancer, lung cancer, and hepatocellular carcinoma $[13,14]$. Breast cancer is reported to be responsible for the most OM, with it being the primary neoplasms of origin of $40 \%$ of the metastases to the orbit and periorbit [13]. These metastases can occur in all compartments in and around the eye. Intraocular metastases are found most frequently in the choroid, which is likely due to its high degree of vascularity [15]. Periocular metastases have also been observed and have a distinct clinical presentation [16].

In a recent literature review, Tsagkaraki et al. described 40 cases in which ILC caused OM [17]. This propensity of ILC to metastasize to the ophthalmic region is underlined by other studies that investigated OM caused by any histological subtype and reported higher rates of ILC that led to OM [18-20], but these studies are limited by small sample size. We employed a natural language processing platform called TIES (Text Information Extraction System) [21] recently described by Jacobsen et al. [22], to search all pathology and radiology reports in a large institutional database. With access to over 2.3 million patients within our UPMC health system with archived radiology or pathology reports [22], we set our objective to test whether OM were more frequent in ILC than in IDC. Further emphasis was put on anatomical features, treatment, and outcome of these cases according to histology.

\section{Methods}

Text Information Extraction System (TIES)

Due to the rarity of OM, we took a unique approach in identifying affected patients. The Text Information Extraction System (TIES) developed by investigators within the Department of Biomedical Informatics at the University of Pittsburgh provided us with the ability to search for specific terms or phrases in pathological and 
radiological reports of all patients treated at UPMC hospitals. All reports in TIES are de-identified. As a natural language processing platform, TIES translates simple search terms into ontologies which are used to search through patient reports. These ontologies consist of the NCI Metathesaurus' synonyms and abbreviations, thus making the search for a specific term not limited by word arrangement or spelling. Temporal combination of two queries consisting of many different ontologies gave us the ability to search for patients that were diagnosed with breast cancer in one report and with $\mathrm{OM}$ in another.

\section{Clinical data}

This retrospective case series does not represent a comprehensive review of all patients seen at our institution, as the initial search through TIES was limited to cases with available pathology and radiology reports. Eligibility criteria were (A) breast cancer confirmed in a pathology report and (B) metastatic involvement of structures in and around the eye suspected clinically and confirmed in either a radiology or pathology report. A filter was set to only include female patients to reduce false positive results. The search criteria in TIES were purposefully broad as to not exclude any OM caused by breast cancer. The search results in TIES were then manually validated to ensure that criteria A and B were met.

After obtaining institutional review board approval from the University of Pittsburgh (IRB Number PRO15050502), we requested identified data for patients in whom the TIES search indicated primary breast cancer and OM. Clinical notes, pathology reports, radiology reports, therapeutic regimens, and outcome for these patients were manually reviewed by members of the investigative clinical team. We will hereafter refer to the resultant group of patients identified by the TIES search and validated by manual chart review as the "OM cohort."

Patient and tumor characteristics for the OM cohort, including histological subtype, estrogen receptor (ER), progesterone receptor (PR), HER2/neu receptor status, involvement of axillary lymph nodes, and initial stage at diagnosis were obtained from available clinical and/or pathology reports. Outcome information including identification of metastatic sites was obtained via review of the treating oncologist's notes, radiology reports, and/or pathology reports. Sites of metastases were grouped into eye, lung, bone, liver, central nervous system (CNS), distant lymph nodes, ovary, peritoneum, gastrointestinal tract, skin, local recurrence, and "other" metastatic sites.

We next compared primary breast tumor characteristics and outcome from the OM cohort to two other large representative cancer patient databases from our institution. First, we used the UPMC Network Cancer Registry, a prospectively curated institutional database of all cancer patients seen at UPMC, to collect information on patients diagnosed with breast cancer between January 1,1990 , and June 1, 2018, who subsequently developed distant metastases. We also compared the OM cohort to a second institutional breast cancer database, the Metastatic Breast Cancer Database. This database includes patients diagnosed with breast cancer and distant metastases and has been prospectively curated at UPMC Magee-Women's Hospital between January 1, 1999, and November 31, 2018.

\section{Immunohistochemistry}

Tumor tissue from three patients identified through TIES was available for histological analysis. Formalin Fixed, Paraffin Embedded (FFPE) paired primary tumor and $\mathrm{OM}$ tissue was available from one patient; only $\mathrm{OM}$ tissue was available for the other two patients. Tissue sections were cut $(4 \mu \mathrm{m})$ and stained, one with hematoxylin and eosin (H\&E), one with an E-cadherin antibody, and one with an estrogen receptor (ER) antibody. For antibody staining, the slides were deparaffinized, rehydrated, and stained using a standard histology protocol. Antigen retrieval was performed using a citrate buffer (Dako, Carpinteria, CA) in a decloaking chamber at $123^{\circ} \mathrm{C}$ before being stained using an Autostainer Plus (Dako) platform with TBST rinse buffer (Dako). The Ecadherin antibody (Mouse monoclonal $-4 \mathrm{~A} 2 \mathrm{C} 7$, Invitrogen, Carlsbad, CA) was applied using a 1:500 dilution at room temperature followed by a secondary antibody of Mach 2 Mouse HRP (Biocare Medical, Pacheco, CA). The ER antibody (Mouse monoclonal - 1D5, Dako) was applied using a 1:100 dilution at room temperature followed by a secondary antibody anti-mouse HiDef HRP Polymer System (Cell Marque, Rocklin, CA). Pictures were taken using a $\times 200$ magnification with the software SPOT imaging.

\section{Statistical analysis}

Time to first $\mathrm{OM}$ was calculated as the time between initial diagnosis of breast cancer and the first diagnosis of metastatic involvement of the orbital or periorbital structures. Disease-free survival (DFS) was calculated as the time from initial breast cancer diagnosis until the first recurrence, while distant metastasis-free survival (DMFS) was defined as the time between the initial breast cancer diagnosis and first diagnosis of a distant metastasis. Survival after OM was calculated as the time between first diagnosis of an $\mathrm{OM}$ and death or last follow-up for censored patients. Overall survival (OS) was calculated as the time between diagnosis of the primary breast cancer and death or last follow-up for censored patients.

$p$ values for continuous variables were calculated using the Wilcoxon rank sum test; Fisher's exact test was used 
for categorical variables, and the log-rank test for survival. Unknown data was removed in all tests. Survival probabilities were estimated using the Kaplan-Meier method. R (3.5.1) was used for all statistical analysis.

\section{Results}

\section{Identification of cases through TIES}

The TIES search yielded 41,590 female breast cancer patients diagnosed between 1981 and 2018. Search criteria of breast cancer and OM yielded 221 cases, but the initial search resulted in a large amount of false positive results. A manual review of the TIES data for these cases eliminated 189 cases in which either primary breast cancer or OM could not be confirmed. Identified data from the remaining 32 patients was then analyzed via a more comprehensive review of the patient medical records. OM originating from a breast primary could not be confirmed in four cases, and those cases were thus excluded. The final resultant OM patient cohort with confirmed breast cancer metastatic to the orbit or periorbit included 28 cases diagnosed between 1995 and 2016 (Fig. 1).

\section{Patient characteristics}

Patient characteristics of the OM cohort are shown in Table 1. The median age at initial diagnosis of breast cancer was 55 (range 28-77 years). ER and PR status were positive in $75.0 \%$ and $60.7 \%$ of the primary tumors, respectively, and HER2/neu status was positive in 10.7\% of cases. The histological subtype of the primary tumor was IDC in 14/28 of the patients (50\%), ILC in $9 / 28$ of the patients (32.1\%), and mixed ILC/IDC subtype in $2 /$ 28 tumors (7.1\%). The histological subtype of $3 / 28$ tumors $(10.7 \%)$ could not be identified.

Comparison of the patient and primary tumor characteristics from the $\mathrm{OM}$ cohort to those patients with any metastases from breast cancer in the UPMC Network Cancer Registry can be found in Table 1 . The relative proportion of patients with ILC and/or mixed histology was significantly higher in the OM cohort compared to all patients with $\mathrm{MBC}$ in the UPMC Network Cancer Registry $(p=0.0007)$. No statistically significant differences in ER, PR, and HER2/neu receptor status between these two groups were found. Patients with $\mathrm{OM}$ were more likely to have higher stages at diagnosis $(p=$ $0.0011)$ and higher frequency of axillary lymph node involvement $(p=0.0492)$ compared to other patients with $\mathrm{MBC}$ in the UPMC Network Cancer Registry.

\section{Anatomical presentation}

In the OM cohort, 10/28 patients (35.7\%) had metastases limited to the left eye, and $9 / 28$ patients $(32.1 \%)$ had a metastasis limited to the right eye. Interestingly, $9 / 28$ patients $(32.1 \%)$ had metastatic involvement of both eyes.
Of these patients, 4/9 had ILC, 1/9 had IDC, 2/9 had mixed ILC/IDC tumor subtype, and 2/9 had unknown tumor subtype. Most (78.6\%) of patients in the OM cohort had OM not effecting the globe, $14.3 \%$ had metastases that were exclusively intraocular, and $7.1 \%$ had tumors with metastatic involvement of ophthalmic tissue inside and outside of the globe. Of the metastases outside of the globe, the majority $(11 / 22,50 \%)$ were in the rectus muscles. Four of these metastases to the extraocular muscles originated from a primary that was solely comprised of IDC. Of the 6 patients with intraocular metastases, 3 had metastases to the optic nerve and 3 had metastases to the choroid. Metastases to the eyelid were reported in $5 / 28$ patients (17.9\%). A detailed representation of the location of all $\mathrm{OM}$ is displayed in Fig. 2a.

\section{Histological analysis}

We performed a histological analysis of three cases from the OM cohort (OM 1, 24, and 26) who had available tumor tissue. For case 24, two samples of the primary breast tumor and one biopsy of the OM was available for review (Fig. 2b). The two breast primary tumor specimens were primarily composed of ILC but also contained IDC cells. We thus confirmed the initial diagnosis of a mixed ILC/IDC subtype. However, interestingly, only ILC cells were present in the paired OM for this patient, as was evident by their negative staining for Ecadherin and their single file growth pattern (Fig. 2b). Biopsies of the OM for cases 1 and 26 were also available for analysis (Fig. 2c). Case 1's primary tumor was of IDC origin according to pathology reports, and the OM also displayed IDC histology. The histological subtype of the primary tumor of case 26 is not known; the OM stained strongly for E-cadherin, suggesting IDC histology.

\section{Survival analysis}

At a median follow-up of 78.4 months after diagnosis of primary breast cancer, $2 / 28$ patients from the OM cohort were still alive $(7.1 \%), 24 / 28$ were confirmed to be deceased (85.7\%), and 2/28 patients were lost to followup (7.1\%). Median overall survival was 82.1 months, with a median DFS of 26.4 months and a median DMFS of 34.2 months. There is no significant difference in OS, DFS, and DMFS in the OM cohort compared to other patients with MBC in the UPMC Network Cancer Registry (Table 1). Median time to first OM was 46.7 months, which was not statistically different between patients with ILC vs. IDC (Fig. 3). Time to first OM in the OM cohort was not significantly different than time to other sites of metastasis in the Metastatic Breast Cancer Database (Additional file 1). DMFS was longer (35.05 months) for patients with ILC compared to patients with 


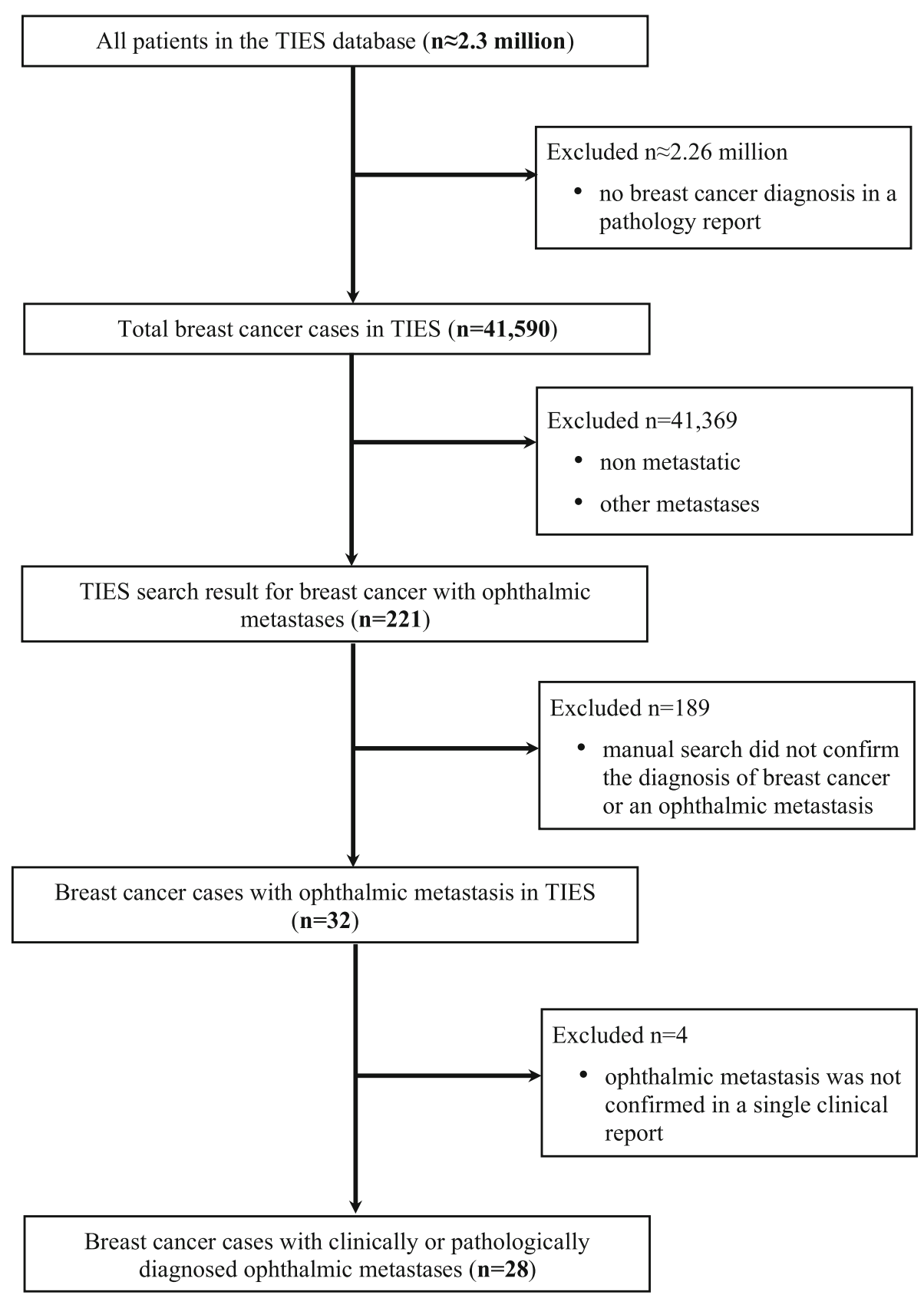

Fig. 1 Consort diagram of patient selection

IDC (23.34 months) in the OM cohort, supporting a tendency for late relapse for ILC. However, after a diagnosis of a first distant metastasis of any kind, the remaining median survival of patients with ILC (21.4 months) was significantly shorter than that of patients with IDC in the OM cohort (55.3 months, $p=0.03$ ) (Fig. 4).

\section{Metastatic pattern}

In the OM cohort, $12 / 28$ patients (42.9\%) developed $\mathrm{OM}$ as their first distant metastasis (Fig. 5). Out of the seven patients with de novo stage IV disease, three had
$\mathrm{OM}$ at the initial presentation. $\mathrm{OM}$ were the second most frequent site of first distant metastasis after bone, which was the first site of distant metastasis in $15 / 28$ patients (53.6\%). Involvement of distant lymph nodes was the first site of distant metastasis in $5 / 28$ patients (17.9\%). While only $2 / 28$ (7.1\%) patients had CNS involvement when they were diagnosed with distant metastatic disease, 13 additional patients later developed CNS metastases as a second or subsequent metastatic event. This proportion of patients $15 / 28$ (53.6\%) in the OM cohort that developed CNS metastases throughout the 
Table 1 Patient characteristics and clinicopathological features of tumors

\begin{tabular}{|c|c|c|c|}
\hline & $\begin{array}{l}\text { Breast cancer primaries with ophthalmic metastasis identified } \\
\text { through TIES (absolute number + percentage) } \\
N=28\end{array}$ & $\begin{array}{l}\text { Metastatic breast cancer in the UPMC Network Cancer } \\
\text { Registry (absolute number + percentage) } \\
N=1366\end{array}$ & $p$ value \\
\hline \multicolumn{4}{|l|}{ Age } \\
\hline $\begin{array}{l}\text { Median age at } \\
\text { diagnosis of primary }\end{array}$ & 55 & 53 & 0.4455 \\
\hline$<50$ at diagnosis & $10(35.7 \%)$ & $520(38.1 \%)$ & 0.847 \\
\hline$\geq 50$ at diagnosis & $18(64.3 \%)$ & 846 (61.9\%) & \\
\hline Race & & & 1 \\
\hline White & $26(92.9 \%)$ & $1248(91.4 \%)$ & \\
\hline Black & $2(7.1 \%)$ & $104(7.6 \%)$ & \\
\hline Others & 0 & $14(1.0 \%)$ & \\
\hline \multicolumn{4}{|c|}{ Survival (median in month) } \\
\hline Overall survival & 82.1 & 58.8 & 0.47 \\
\hline Disease-free survival & 26.4 & 35.4 & 0.52 \\
\hline $\begin{array}{l}\text { Distant metastasis- } \\
\text { free survival }\end{array}$ & 34.2 & 36.6 & 0.76 \\
\hline $\begin{array}{l}\text { Histological } \\
\text { subtypes }\end{array}$ & & & 0.00067 \\
\hline IDC & $14(50.0 \%)$ & $1167(85.4 \%)$ & \\
\hline ILC & $9(32.1 \%)$ & 155 (11.3\%) & \\
\hline Mixed & $2(7.1 \%)$ & 44 (3.2\%) & \\
\hline Unknown & $3(10.7 \%)$ & 0 & \\
\hline Stage & & & 0.00106 \\
\hline Stage 0 & & $11(0.8 \%)$ & \\
\hline Stage I & $0(0 \%)$ & $340(24.9 \%)$ & \\
\hline Stage $\|$ & $5(17.9 \%)$ & $573(41.9 \%)$ & \\
\hline Stage III & $7(25.0 \%)$ & $186(13.6 \%)$ & \\
\hline Stage IV & $7(25.0 \%)$ & $184(13.5 \%)$ & \\
\hline Stage unknown & $9(32.1 \%)$ & $72(5.3 \%)$ & \\
\hline Lymph node status & & & 0.04927 \\
\hline Positive & $18(64.3 \%)$ & $814(59.6 \%)$ & \\
\hline Negative & $2(7.1 \%)$ & $386(28.3 \%)$ & \\
\hline Unknown & $8(28.6 \%)$ & $166(12.2 \%)$ & \\
\hline ER status & & & 0.2597 \\
\hline ER+ & $21(75.0 \%)$ & 981 (71.8\%) & \\
\hline ER- & $4(14.3 \%)$ & 385 (28.2\%) & \\
\hline Unknown & $3(10.7 \%)$ & 0 & \\
\hline PR status & & & 0.2809 \\
\hline PR+ & $17(60.7 \%)$ & 805 (58.9\%) & \\
\hline PR- & $6(21.4 \%)$ & 519 (38.0\%) & \\
\hline PR unknown & 5 (17.9\%) & $42(3.1 \%)$ & \\
\hline HER2 status & & & 1 \\
\hline HER2/neu + & $3(10.7 \%)$ & 51 (3.7\%) & \\
\hline HER2/neu - & $20(71.4 \%)$ & 277 (20.3\%) & \\
\hline Equivocal & 0 & $9(0.7 \%)$ & \\
\hline HER2/neu unknown & $5(17.9 \%)$ & $1029(75.3 \%)$ & \\
\hline
\end{tabular}

IDC invasive ductal carcinoma, ILC invasive lobular carcinoma, ER estrogen receptor, PR progesterone receptor, HER2/neu human epidermal growth factor receptor 


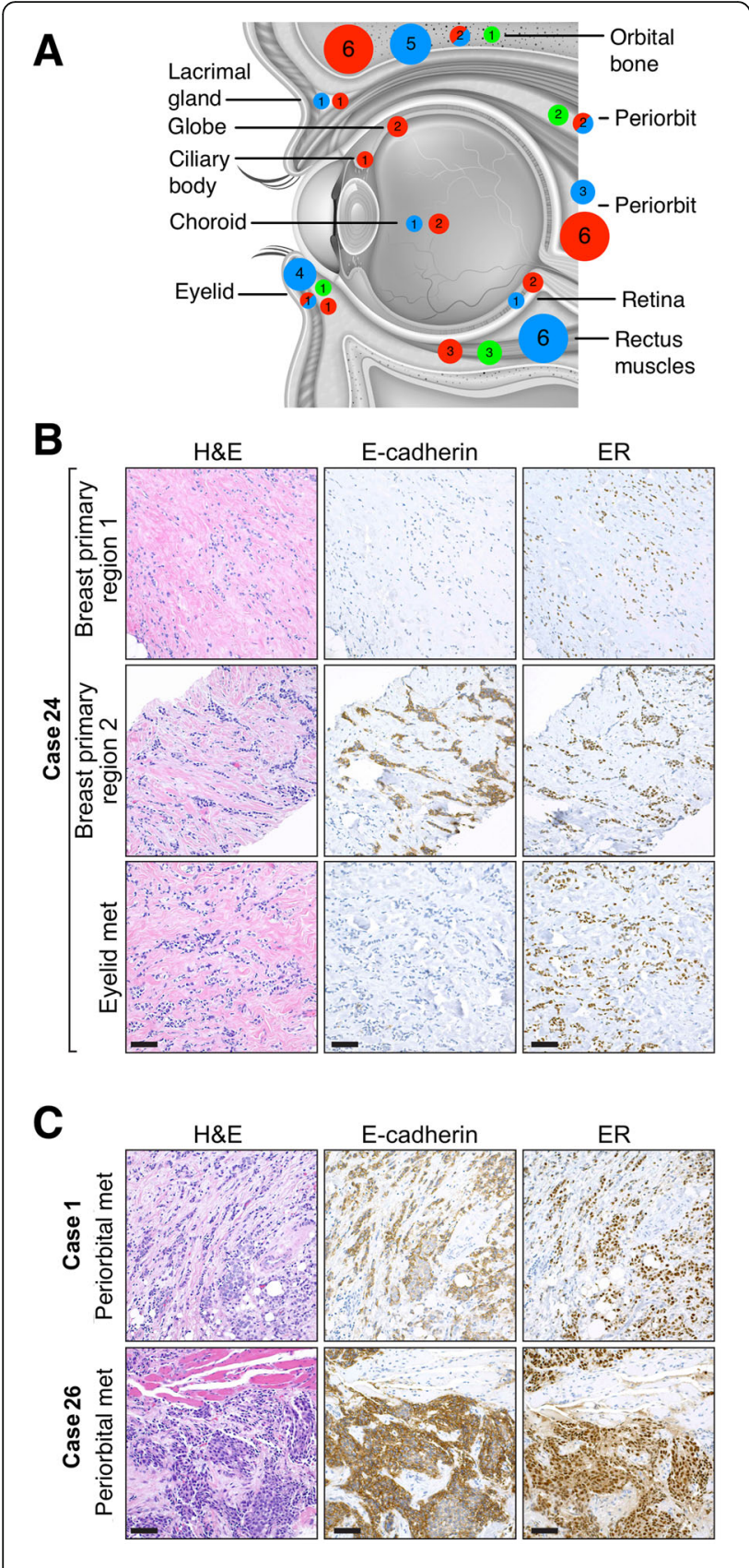

Fig. 2 Anatomy and histology of OM. a Representation of the anatomical location of all OM. Red dots represent metastases from an IDC primary, blue dots represent metastases from an ILC primary, mixed red and blue dots represent metastases from a mixed IDC/ILC primary, and green dots represent metastases from a primary of unknown histological subtype. Numbers indicate how many patients were affected by OM to this location. In cases where patients had $\mathrm{OM}$ to multiple locations within the ophthalmic region, each location was displayed separately. Graphic courtesy of Shutterstock [23]. $\mathbf{b}$ Histologic analysis of the primary breast tumor for case 24 shows a mixed pattern of invasive lobular and ductal carcinoma. The majority of the tumor is composed of lobular carcinoma, showing single infiltrating cells and linear cords of cells dissecting stroma, which are negative for E-cadherin staining but positive for ER (top row). A discrete, although minor component of the tumor is composed of somewhat larger infiltrating cells forming clusters; these clusters are strongly E-cadherin positive and ER positive (middle row). The biopsy of metastatic disease in the left lower eyelid shows only lobular pattern metastatic carcinoma that is Ecadherin negative and ER positive (bottom row). c Two other cases of periorbital metastatic breast cancer in unrelated patients are shown. For these cases, the primary breast cancer specimens were not available for review. In both cases, the histologic features of metastatic carcinoma show some lobular pattern infiltration, particularly for case 1, but features that are more in keeping with metastatic ductal carcinoma. E-cadherin staining is strongly and diffusely positive for both cases, and both are ER positive. Scale bar $=100 \mu \mathrm{m}$

course of their disease is significantly higher than the 420/1495 (28.1\%) of patients in the Metastatic Breast Cancer Database that developed CNS metastases $(p=$ 0.0053). CNS metastases preceded the diagnosis of OM in $2 / 15$ patients $(13.3 \%)$, they were diagnosed after the $\mathrm{OM}$ in $6 / 15$ patients $(40.0 \%)$, and finally they were diagnosed concurrently with $\mathrm{OM}$ in $7 / 15$ patients $(46.7 \%)$. Of note, only 4 of the 15 CNS metastases (26.7\%) originated from an ILC primary. The most frequent sites of distant metastases throughout the course of the disease other than the ophthalmic region were bone $(16 / 28$; 92.9\%), CNS (15/28; 53.6\%), liver (12/28; 42.9\%), distant lymph nodes $(12 / 28 ; 42.9 \%)$, and lung $(9 / 28 ; 32.1 \%)$. A detailed representation of the chronological sequence of metastatic progression for all 28 patients is displayed in Fig. 5 (detailed data in Additional file 2). The earliest metastases after diagnosis of the primary breast cancer in the OM cohort were bony metastases (median 43.6 months), followed by OM (median 46.7 months), and then metastases to distant lymph nodes (median 55.0 months). These were then succeeded by CNS metastases (median 63.0 months), liver metastases (median 69.4 months), and lung metastases (median 70.4 months).

\section{Clinical management}

Of the 28 patients with OM, 14 received adjuvant hormonal therapy. The number of lines of systemic therapy for metastatic disease for all patients in the OM cohort can be seen in Table 2. Anastrozole was the most 


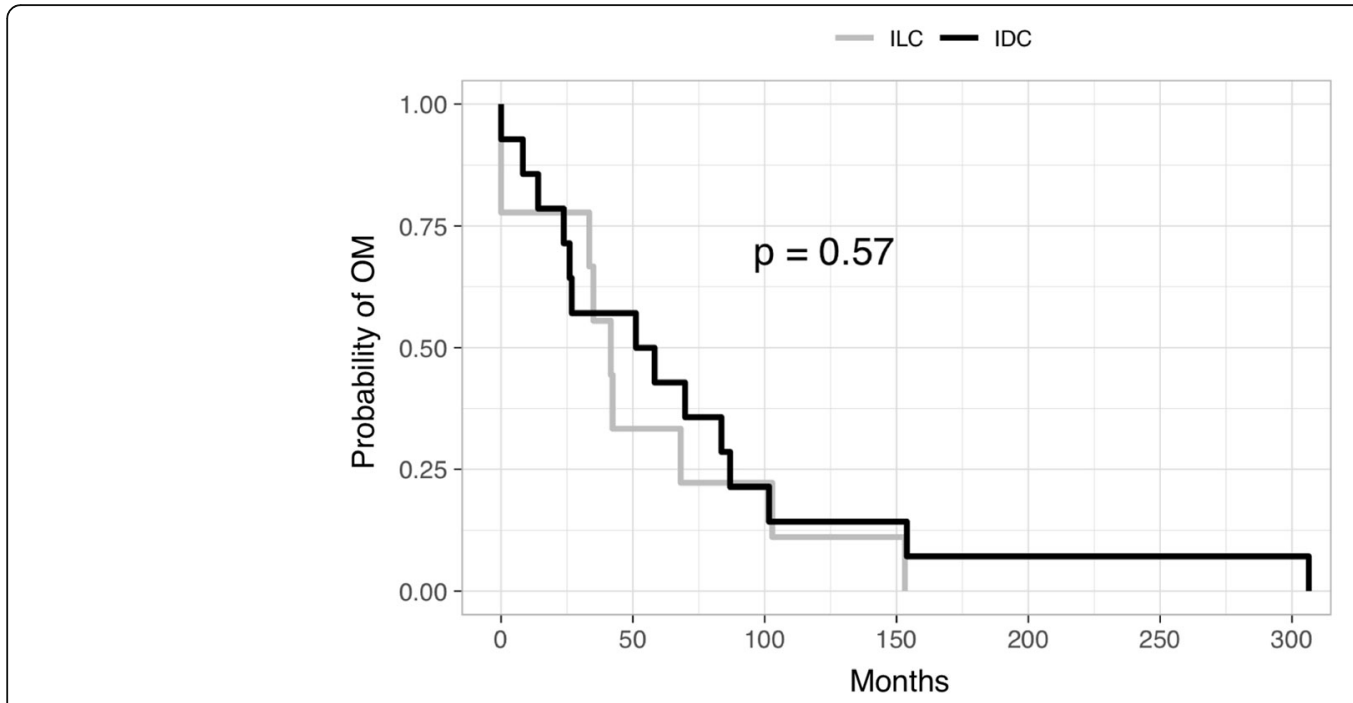

Number at risk

\begin{tabular}{c|ccccccc|}
\hline ILC & 9 & 3 & 2 & 1 & 0 & 0 & 0 \\
\hline 14 & 8 & 3 & 2 & 1 & 1 & 1 \\
\hline 0 & 50 & 100 & $\begin{array}{c}150 \\
\text { Months }\end{array}$ & 200 & 250 & 300 \\
\hline
\end{tabular}

Fig. 3 Probability of first ophthalmic metastasis in patients with IDC and ILC

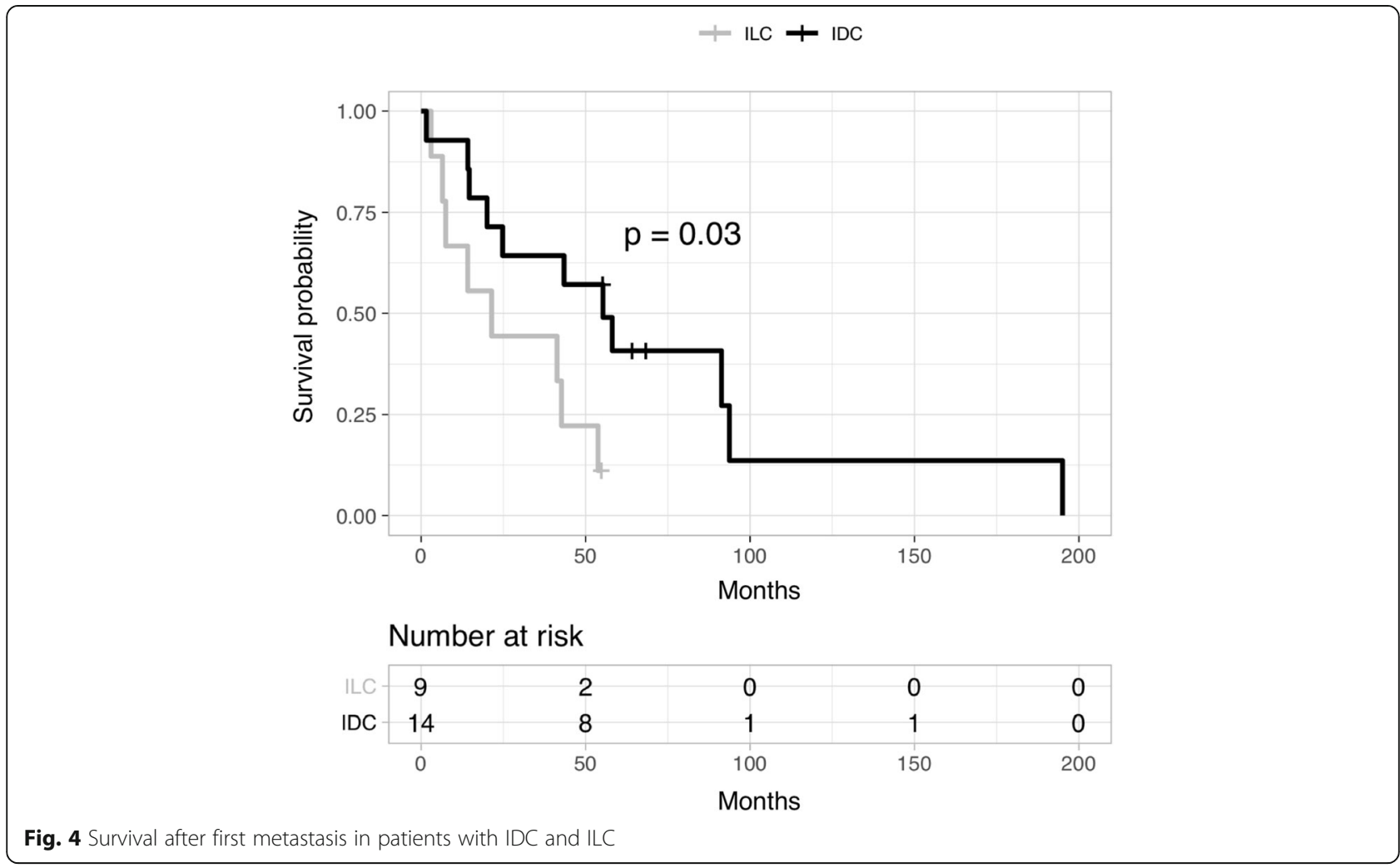




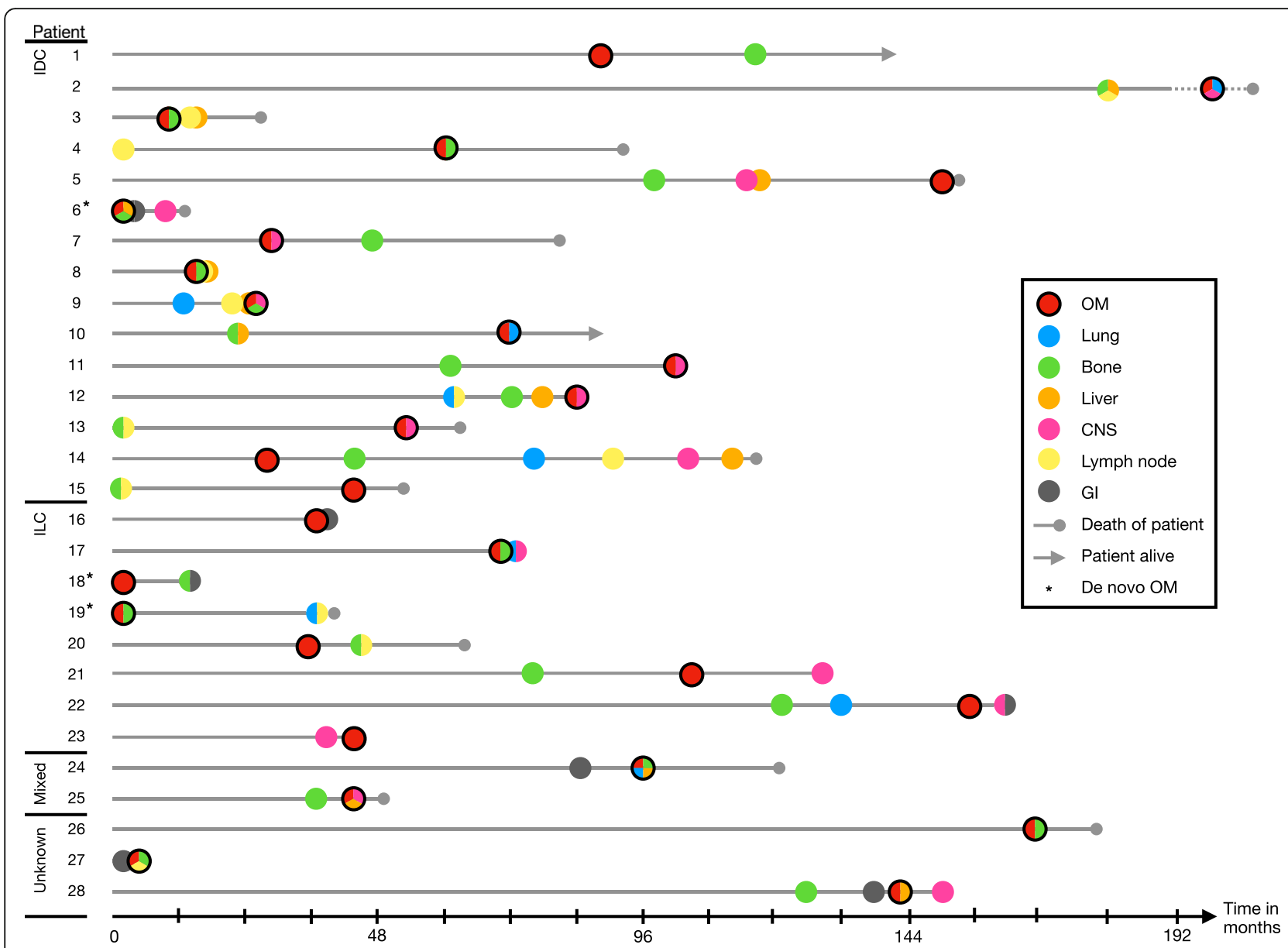

Fig. 5 Metastatic sequence for patients in the OM cohort. For each patient, the time from diagnosis of primary breast cancer to the diagnosis of a new metastatic site is displayed. Metastatic sites are color coded as follows: OM: red, lung: blue, bone: green, liver: orange, CNS: pink, distant lymph node: yellow, gastrointestinal tract: gray. If multiple metastatic sites were diagnosed within 1 month, they are displayed with a circle in multiple, corresponding colors. Solid gray circle at the end of timeline indicates death of patient; timelines for patients that were alive at the time of analysis end with an arrow. An asterisk after the patient number denotes the presence of de novo OM

frequently administered first-line therapy for advanced disease (to 7 patients), followed by Fulvestrant (to 4 patients) and then Tamoxifen, Capecitabine, Letrozole, Docetaxel, and Paclitaxel (the latter 5 were all administered to 3 patients as first-line therapy). Second-line therapies were most frequently Fulvestrant, Capecitabine, and Anastrozole (to 5, 4, and 3 patients respectively) while as third-line therapies, Fulvestrant was administered most frequently (to 6 patients), followed by Tamoxifen, Docetaxel, and Mitoxantrone (all administered to 3 patients). ER-positive and ER-negative patients were included in this analysis.

We identified $20 / 28$ patients in the OM cohort (71.4\%) with available radiation records. Four of these patients received radiation therapy more than once, sometimes to different sites (see Table 2), resulting in 25 separate treatments. The most common locations treated were the entire orbit $(13 / 25,52 \%)$, followed by the eyelid $(5 / 25,20 \%)$, retrobulbar area $(4 / 25,16 \%)$, and intraocular area $(3 / 25,12 \%)$. The median dose prescribed was 30 Gray (Gy) (range 10-60 Gy) in 12 (range 2-30 fractions) fractions. The most common radiation technique utilized was 3D-conformal for $16 / 25$ treatments (64\%), electron for $5 / 25$ treatments (20\%), intensity-modulated radiation therapy (IMRT) for $3 / 25$ treatments $(12 \%)$, and 1 patient received stereotactic body radiation therapy (SBRT) $(4 \%)$.

\section{Discussion}

Our initial TIES search of a database including over 2.5 million patient records led to the identification of $28 \mathrm{pa}$ tients with $\mathrm{OM}$ from breast cancer, making our study the largest to date of these events. The use of the natural language processing platform TIES enabled high sensitivity to identify these extremely rare breast cancer metastases.

OM can present in many ways and most often indicate poor prognosis $[24,25]$; $92 \%$ of our patients in the OM 
Table 2 Description of individual patients in OM cohort

\begin{tabular}{|c|c|c|c|c|c|c|c|c|c|c|}
\hline Patient & $\begin{array}{l}\text { Histology } \\
\text { of primary } \\
\text { breast } \\
\text { cancer }\end{array}$ & $\begin{array}{l}\text { Site of first distant } \\
\text { metastasis }\end{array}$ & $\begin{array}{l}\text { Time to first } \\
\text { distant } \\
\text { metastasis in } \\
\text { months }\end{array}$ & $\begin{array}{l}\text { Location of } \\
\text { OM }\end{array}$ & $\begin{array}{l}\text { Time to } \\
\text { OM in } \\
\text { months }\end{array}$ & $\begin{array}{l}\text { Side of } \\
\text { OM }\end{array}$ & $\begin{array}{l}\text { Location of } \\
\text { XRT therapy } \\
\text { to OM }\end{array}$ & $\begin{array}{l}\text { Survival } \\
\text { in } \\
\text { months } \\
\text { after OM }\end{array}$ & $\begin{array}{l}\text { CNS } \\
\text { metastasis }\end{array}$ & $\begin{array}{l}\text { Number of } \\
\text { systemic therapy } \\
\text { lines for } \\
\text { metastatic cancer }\end{array}$ \\
\hline 1 & IDC & Ophthalmic & 86.8 & $\begin{array}{l}\text { Orbital bone, } \\
\text { Rectus } \\
\text { muscles }\end{array}$ & 86.8 & Right & Orbital bone & $\begin{array}{l}55.8 \\
\text { (alive) }\end{array}$ & No & 2 \\
\hline 2 & IDC & $\begin{array}{l}\text { Adrenal glands, } \\
\text { bone, CNS, } \\
\text { distant lymph } \\
\text { nodes, liver }\end{array}$ & 178.1 & $\begin{array}{l}\text { Choroid, } \\
\text { ciliary body }\end{array}$ & 294.1 & Right & Choroid & 79.0 & Yes & 8 \\
\hline 3 & IDC & Ophthalmic, bone & 8.2 & $\begin{array}{l}\text { Retro-orbital } \\
\text { fat, globe, } \\
\text { orbital bone }\end{array}$ & 8.2 & Right & Orbital bone & 20.1 & No & 5 \\
\hline 4 & IDC & $\begin{array}{l}\text { Distant lymph } \\
\text { node }\end{array}$ & 14.3 & $\begin{array}{l}\text { Rectus } \\
\text { muscles, } \\
\text { lacrimal gland, } \\
\text { orbital bone }\end{array}$ & 58.2 & Right & Orbital bone & 35.5 & No & 11 \\
\hline 5 & IDC & Bone, spleen & 96.0 & $\begin{array}{l}\text { Retro-orbital } \\
\text { fat }\end{array}$ & 153.8 & Bilateral & No XRT & 0.2 & Yes & 6 \\
\hline 6 & IDC & $\begin{array}{l}\text { Ophthalmic, } \\
\text { bone, liver }\end{array}$ & 0 & Orbital bone & 0 & Left & No XRT & 14.3 & Yes & 3 \\
\hline 7 & IDC & Ophthalmic, CNS & 26.8 & $\begin{array}{l}\text { Choroid, } \\
\text { retina }\end{array}$ & 26.8 & Right & Choroid & 55.2 & Yes & 3 \\
\hline 8 & IDC & Ophthalmic, bone & 14.1 & Orbital bone & 14.1 & Left & Orbital bone & 1.7 & No & 0 \\
\hline 9 & IDC & Lung & 10.9 & Retina & 23.8 & Left & Retina & 1.8 & Yes & 3 \\
\hline 10 & IDC & Bone, liver & 20.7 & $\begin{array}{l}\text { Orbital bone, } \\
\text { Periorbital soft } \\
\text { tissue }\end{array}$ & 69.8 & Left & Orbital bone & $\begin{array}{l}22.8 \\
\text { (alive) }\end{array}$ & No & 5 \\
\hline 11 & IDC & Bone & 59.1 & $\begin{array}{l}\text { Orbital soft } \\
\text { tissue }\end{array}$ & 101.6 & Left & No XRT & 1.0 & Yes & 4 \\
\hline 12 & IDC & $\begin{array}{l}\text { Distant lymph } \\
\text { nodes, lung }\end{array}$ & 59.8 & Globe & 83.5 & Left & No XRT & 1.1 & Yes & 8 \\
\hline 13 & IDC & $\begin{array}{l}\text { Contralateral } \\
\text { breast, distant } \\
\text { lymph nodes }\end{array}$ & 0 & $\begin{array}{l}\text { Eyelid, } \\
\text { periorbit }\end{array}$ & 51.1 & Left & Eyelid & $\begin{array}{l}\text { Lost to } \\
\text { follow- } \\
\text { up }\end{array}$ & Yes & 4 \\
\hline 14 & IDC & Ophthalmic & 26.0 & Rectus muscle & 26.0 & Right & No XRT & 91.3 & Yes & 6 \\
\hline 15 & ILC & $\begin{array}{l}\text { Bone, distant } \\
\text { lymph nodes }\end{array}$ & 0 & $\begin{array}{l}\text { Orbital bone, } \\
\text { eye lid, } \\
\text { lacrimal gland }\end{array}$ & 41.6 & Bilateral & $\begin{array}{l}\text { Orbital } \\
\text { bone, eyelid }\end{array}$ & 12.1 & No & 8 \\
\hline 16 & ILC & Ophthalmic & 35.0 & $\begin{array}{l}\text { Rectus } \\
\text { muscles }\end{array}$ & 35.0 & Left & No XRT & 3.0 & No & 1 \\
\hline 17 & ILC & Ophthalmic, bone & 70 & Rectus muscle & 70.0 & Right & Orbital bone & 4.6 & Yes & 2 \\
\hline 18 & ILC & $\begin{array}{l}\text { Ophthalmic, } \\
\text { peritoneum }\end{array}$ & 0 & $\begin{array}{l}\text { Retina, } \\
\text { choroid, } \\
\text { rectus muscle }\end{array}$ & 0 & Left & No XRT & 14.1 & No & 0 \\
\hline 19 & ILC & Ophthalmic, bone & 0 & $\begin{array}{l}\text { Rectus } \\
\text { muscles }\end{array}$ & 0 & Bilateral & No XRT & 41.3 & No & 5 \\
\hline 20 & ILC & Ophthalmic & 33.4 & $\begin{array}{l}\text { Eyelid, } \\
\text { periorbital soft } \\
\text { tissue, orbital } \\
\text { bone }\end{array}$ & 33.4 & Bilateral & Both eyelids & 21.5 & No & 2 \\
\hline 21 & ILC & Bone & 74.0 & $\begin{array}{l}\text { Rectus } \\
\text { muscle, orbital } \\
\text { bone }\end{array}$ & 102.8 & Bilateral & Orbital bone & $\begin{array}{l}\text { Lost to } \\
\text { follow- } \\
\text { up }\end{array}$ & No & 5 \\
\hline 22 & ILC & $\begin{array}{l}\text { Bone, } \\
\text { contralateral } \\
\text { breast, thyroid }\end{array}$ & 119.2 & $\begin{array}{l}\text { Orbital bone, } \\
\text { eyelid }\end{array}$ & 153.1 & Right & Orbital bone & 8.7 & Yes & 7 \\
\hline
\end{tabular}


Table 2 Description of individual patients in OM cohort (Continued)

\begin{tabular}{|c|c|c|c|c|c|c|c|c|c|c|}
\hline Patient & $\begin{array}{l}\text { Histology } \\
\text { of primary } \\
\text { breast } \\
\text { cancer }\end{array}$ & $\begin{array}{l}\text { Site of first distant } \\
\text { metastasis }\end{array}$ & $\begin{array}{l}\text { Time to first } \\
\text { distant } \\
\text { metastasis in } \\
\text { months }\end{array}$ & $\begin{array}{l}\text { Location of } \\
\text { OM }\end{array}$ & $\begin{array}{l}\text { Time to } \\
\text { OM in } \\
\text { months }\end{array}$ & $\begin{array}{l}\text { Side of } \\
\text { OM }\end{array}$ & $\begin{array}{l}\text { Location of } \\
\text { XRT therapy } \\
\text { to OM }\end{array}$ & $\begin{array}{l}\text { Survival } \\
\text { in } \\
\text { months } \\
\text { after OM }\end{array}$ & $\begin{array}{l}\text { CNS } \\
\text { metastasis }\end{array}$ & $\begin{array}{l}\text { Number of } \\
\text { systemic therapy } \\
\text { lines for } \\
\text { metastatic cancer }\end{array}$ \\
\hline & & gland & & & & & & & & \\
\hline 23 & ILC & CNS & 36.6 & $\begin{array}{l}\text { Retrobulbar } \\
\text { soft tissue }\end{array}$ & 42.2 & Left & $\begin{array}{l}\text { Twice } \\
\text { retrobulbar }\end{array}$ & 1.8 & Yes & 3 \\
\hline 24 & $\begin{array}{l}\text { Mixed IDC } \\
\text { and ILC }\end{array}$ & Rectum & 82.6 & $\begin{array}{l}\text { Rectus } \\
\text { muscles, } \\
\text { eyelid }\end{array}$ & 94.0 & Bilateral & $\begin{array}{l}\text { Retrobulbar, } \\
\text { eyelid }\end{array}$ & 24.7 & No & 5 \\
\hline 25 & $\begin{array}{l}\text { Mixed IDC } \\
\text { and ILC }\end{array}$ & Bone & 34.9 & Orbital bone & 41.6 & Bilateral & Orbital bone & 8.7 & Yes & 3 \\
\hline 26 & Unknown & Ophthalmic, bone & 165.0 & $\begin{array}{l}\text { Orbital bone, } \\
\text { rectus } \\
\text { muscles }\end{array}$ & 165 & Right & Orbital bone & 14.2 & No & 0 \\
\hline 27 & Unknown & $\begin{array}{l}\text { Gastrointestinal } \\
\text { tract, peritoneum }\end{array}$ & 0 & $\begin{array}{l}\text { Rectus } \\
\text { muscles, } \\
\text { eyelid, orbital } \\
\text { bone }\end{array}$ & 2.8 & Bilateral & Retrobulbar & 4.3 & No & 2 \\
\hline 28 & Unknown & Bone & 122.7 & $\begin{array}{l}\text { Orbital and } \\
\text { periorbital soft } \\
\text { tissue }\end{array}$ & 140.5 & Bilateral & Retrobulbar & 10.0 & Yes & 3 \\
\hline
\end{tabular}

$X R T$ radiation therapy

cohort died from metastatic breast cancer. Of all tumors types, breast cancer is responsible for most OM [13], and the ILC histological subtype has been described to cause OM more commonly than IDC $[18,20]$. We set out to test this hypothesis in a large institutional cohort and to further characterize patient experience in the setting of $\mathrm{OM}$ via a descriptive analysis of their histologic, anatomic, treatment and survival data.

Compared to 1366 patients in the UPMC Cancer Network registry, we observed higher rates of lymph node positivity and higher stages at diagnosis in the OM cohort. We also observed a significant association of $\mathrm{OM}$ with a diagnosis of an ILC primary. This confirms earlier reports and emphasizes the need to take OM into consideration when treating patients with ILC, especially in those with complaints of visual disturbances.

A study conducted by Parrozzani et al. reported that patients with choroidal metastases are more likely to have an ER-positive and PR-positive primary breast cancer than patients with breast cancer metastasizing to any other location [26]. In a recent cohort description of orbital metastases by Sindoni et al., they were all ER positive [27]. In our study, ER, PR, and HER2/neu receptor status of primary tumors that led to OM did not differ significantly from the receptor status of other primary breast tumors in a large institutional database of patients with metastatic breast cancer.

OM were diagnosed as the first site of distant metastasis in 12 of 28 patients in the OM cohort, making them the second most frequent site of first distant metastasis after bony metastases. In their literature review, Tsagkaraki et al. have described changes in vision, swelling, and pain as the most frequent symptoms of OM [17], and physicians should consider OM in patients with these complaints. In a comparison with site specific data from the Metastatic Breast Cancer Database, the time between diagnosis of primary breast cancer and OM (median 46.7 months) did not differ significantly from the time to development of distant metastasis to any other site. The sequence of appearance of new metastatic sites in the OM cohort was bony metastases, OM, distant lymph nodes, CNS, liver, and lung; however, such analysis is hampered by limited sample size. Survival after diagnosis of the first distant metastasis was significantly shorter for patients with ILC than for patients with IDC in the OM cohort. In an earlier study focusing on metastatic breast cancer by histology, we found no such difference in outcome after diagnosis of distant metastasis between ILC and IDC [10]. The overall survival in the OM cohort (median 82.1 months), however, did not differ from the survival of other patients with metastatic breast cancer in the two other databases at our institution. Similar overall survival has also been reported in the literature [28]. This leads us to the conclusion that $\mathrm{OM}$ are not a sign of shortened OS from time of diagnosis when compared to breast cancer that metastasizes to other locations. However, early detection and treatment of $\mathrm{OM}$ should be a priority for treating physicians, as impaired 
vision leads to a deterioration of quality of life [29]. Additionally, survival times were short in many of the patients after a diagnosis of OM.

Many of the OM in the cohort were in extraocular tissue, with half of these infiltrating the extraocular muscles. In 4 of these cases, the metastasis originated from an IDC breast primary tumor. We are aware of only 5 such cases previously reported in the English literature [30] and thus believe that the TIES search for OM at our institution allowed for an extremely high degree of sensitivity for identification of these rare cases.

Bone was the most frequent other site of distant metastasis in the 28 patients with OM, followed by metastases to the central nervous system (53.6\%). While brain metastases have been identified as a risk factor for choroidal metastases [31], our study is, to our knowledge, the first to report an association between metastases to orbit and periorbit and metastases to the CNS. We observed that CNS metastases were most often diagnosed at the same time or after the diagnosis of OM in our cohort. This observation supports consideration of increased screening for CNS metastases in patients with OM.

While small sample size for this study limits our ability to draw strong conclusions, several findings from this work are worthy of clinical consideration and future investigations. The co-occurrence of OM and CNS metastases was less pronounced in ILC in our cohort; only 4 of the 15 CNS metastases were caused by an ILC primary. This may indicate a different pattern of spread for OM from ILC versus from IDC. We speculate that ILC cells are biologically distinct and thus metastasize to the ophthalmic region via different mechanisms than IDC cells, but larger studies are needed to address this question.

Of the $28 \mathrm{OM}, 9$ were bilateral. Of these 9,4 originated from ILC and 2 from a mixed IDC/ILC subtype, showing a trend for ILC being more likely to metastasize to both eyes. Interestingly, in one of the patients with a mixed IDC/ILC primary breast tumor, the OM was comprised solely of ILC cells. This adds further support to unique mechanisms of metastasis to the orbit and periorbit for ILC. Raape et al. have speculated that a high amount of estrogen produced in the eye provides a favorable niche for breast cancer metastases, and more specifically ILC [17]. This hypothesis is supported by reports of high ER expression in the retina, lens ciliary body, and iris [32] and high aromatase expression in the lens epithelial cells [33]. However, 15\% of the OM in our cohort arose from ER-negative primary tumors, demonstrating the need for further investigation of this hypothesis through analysis of additional clinical samples, and mechanistic analyses.

Given the retrospective case series analysis of our study, we were dependent on available clinical, radiology, and pathology notes. Not all OM in our cohort were histologically confirmed; in many cases, we only had histological information from the primary tumor. However, our study has some notable strengths. We have been able to identify a large number of patients with a rare condition via the natural language processing platform TIES. We were also able to analyze clinical notes and modes of therapy in addition to radiological and histological reports, thus providing a broad understanding of patients with $\mathrm{OM}$ as unique metastases from breast cancer.

\section{Conclusions}

We provide a comprehensive description of OM originating from breast cancer, including data on histology, anatomical presentation, treatment, and survival. OS of patients in the OM cohort was similar to that of patients with other metastases. Our experience supports an increased association of OM from breast cancer with the ILC histological subtype, and survival after diagnosis of a first distant metastasis was significantly shorter for patients with ILC vs. IDC in our OM cohort. Furthermore, we show an association between OM and CNS metastases and a considerable number of cases with bilateral $\mathrm{OM}$, points that are important to consider when treating patients with OM.

\section{Supplementary information}

Supplementary information accompanies this paper at https://doi.org/10. 1186/s13058-020-01309-3.

Additional file 1. Comparison of time from diagnosis of the primary tumor to a site-specific first metastases. Displayed is a comparison of the time to first ophthalmic metastasis with the time to first metastasis at a specific anatomical site. Data on the time to first metastasis at a specific anatomical site was abstracted from the Metastatic Breast Cancer Database.

Additional file 2. Time to Metastasis by Site for Individual Patients.

\begin{abstract}
Abbreviations
OM: Ophthalmic metastasis; ILC: Invasive lobular carcinoma; IDC: Invasive ductal carcinoma; CNS: Central nervous system; HER2/neu: Human epidermal growth factor receptor 2; ER: Estrogen receptor; PR: Progesterone receptor; DFS: Disease-free survival; DMFS: Distant metastasis-free survival; OS: Overall survival; Gy: Gray
\end{abstract}

Acknowledgements

We would like to thank Melissa Schwenk and the Department of Biomedical Informatics at the University of Pittsburgh for their expertise on TIES.

Additionally, we would like to thank Christina Kline and the Pitt Biospecimen Core for their support in acquiring tissue of ophthalmic metastases.

\section{Authors' contributions}

$M B, J A, A L, S O$, and RJ designed the study. MR and $A B$ compiled and provided access to the clinical databases. MB and RJ analyzed the data. SB and JR provided data and analysis on the radiation therapy. LZ and GT performed the statistical analysis. PL undertook the histological analysis. MB, $A L, S O$, and $R J$ interpreted the results. MB wrote the manuscript. All authors reviewed and approved the final manuscript. 


\section{Funding}

The work is in part funded by a Susan G Komen leadership award to Dr. Oesterreich (SAC160073), the Nicole Meloche Foundation, Shear Family Foundation, the Metastatic Breast Cancer Network [S.O.]. RJ is supported by a Susan G Komen Career Development Award (CCR14300865). AL is supported by a Susan G Komen Scholar Award (SAC150021). This project used the UPMC Hillman Cancer Center Tissue and Research Pathology/Pitt Biospecimen Core shared resource which is supported in part by award P30CA047904. The TIES system is supported by Grant Number U24CA180921 from the National Cancer Institute (NCl).

\section{Availability of data and materials}

The datasets generated during and/or analyzed during the current study are available from the corresponding author on reasonable request.

\section{Ethics approval and consent to participate} Not applicable.

\section{Consent for publication}

Not applicable.

\section{Competing interests}

The authors declare that they have no competing interests.

\section{Author details}

${ }^{1}$ Department of Pharmacology \& Chemical Biology, University of Pittsburgh, Pittsburgh, PA, USA. ${ }^{2}$ Charité - Universitätsmedizin Berlin, Berlin, Germany. ${ }^{3}$ Women's Cancer Research Center, UPMC Hillman Cancer Center, Magee Women's Research Institute, Pittsburgh, PA, USA. ${ }^{4}$ Department of Biostatistics, University of Pittsburgh, Pittsburgh, PA, USA. ${ }^{5}$ University of Pittsburgh School of Medicine, Department of Radiation Oncology, UPMC Hillman Cancer Center, Pittsburgh, PA, USA. ${ }^{6}$ School of Nursing, University of Pittsburgh, Pittsburgh, PA, USA. ' University of Pittsburgh School of Medicine, Department of Medicine, Division of Hematology/Oncology, UPMC Hillman Cancer Center, Pittsburgh, PA, USA. ${ }^{8}$ Department of Pathology, University of Pittsburgh, Pittsburgh, PA, USA. ${ }^{9}$ Department of Medicine, Division of Hematology/Oncology, Perelman School of Medicine, Abramson Cancer Center, University of Pennsylvania, Philadelphia, PA, USA. ${ }^{10}$ Rena Rowan Breast Center, Perelman Center for Advanced Medicine and the Abramson Cancer Center, 3rd Floor, West Pavilion, 3400 Civic Center Boulevard, Philadelphia, PA 19104, USA.

\section{Received: 10 February 2020 Accepted: 10 June 2020}

\section{Published online: 26 June 2020}

\section{References}

1. Ghoncheh $M$, Pournamdar $Z$, Salehiniya $H$. Incidence and mortality and epidemiology of breast cancer in the world. Asian Pac J Cancer Prev. 2016; 17(S3):43-6.

2. Li C, Anderson B, Daling J, Moe R. Trends in incidence rates of invasive lobular and ductal breast carcinoma. J Am Med Assoc. 2003:289:1421-4.

3. McCart Reed AE, Kutasovic JR, Lakhani SR, Simpson PT. Invasive lobular carcinoma of the breast: morphology, biomarkers and 'omics. Breast Cancer Res. 2015;17(1):12

4. Rakha EA, Ellis 1O. Lobular breast carcinoma and its variants. Semin Diagn Pathol. 2010;27:49-61.

5. Arpino G, Bardou VJ, Clark GM, Elledge RM. Infiltrating lobular carcinoma of the breast: tumor characteristics and clinical outcome. Breast Cancer Res. 2004;6(3):R149-56.

6. Chen Z, Yang J, Li S, Lv M, Shen Y, Wanf B, et al. Invasive lobular carcinoma of the breast: a special histological type compared with invasive ductal carcinoma. PLoS One. 2017;12(9):e0182397.

7. Tubiana-Hulin M, Stevens D, Lasry S, Guinebretière JM, Bouita L, Cohen-Solal $C$, et al. Response to neoadjuvant chemotherapy in lobular and ductal breast carcinomas: a retrospective study on 860 patients from one institution. Ann Oncol. 2006;17(8):1228-33.

8. Metzger FO, Giobbie-Hurder A, Mallon E, Gusterson B, Viale G, Winer EP et al. Relative effectiveness of letrozole compared with tamoxifen for patients with lobular carcinoma in the BIG 1-98 trial. J Clin Oncol. 2015; 33(25):2772-9.
9. Pestalozzi BC, Zahrieh D, Mallon E, Gusterson BA, Price KN, Gelber RD, et al. Distinct clinical and prognostic features of infiltrating lobular carcinoma of the breast: combined results of 15 International Breast Cancer Study Group clinical trials. J Clin Oncol. 2008:26:3006-14.

10. Mathew A, Rajapogal P, Villgran V, Sandhu G, Jankowitz R, Jacob M, et al. Distinct pattern of metastases in patients with invasive lobular carcinoma of the breast. Geburtshilfe Frauenheilkd. 2017;77:660-6.

11. He H, Gonzalez A, Robinson E, Yang WT. Distant metastatic disease manifestations in infiltrating lobular carcinoma of the breast. AJR Am J Roentgenol. 2014;202(5):1140-8.

12. Inoue $M$, Nakagomi $H$, Nakada $H$, Furuya $K$, Ikegame $K$, Watanabe $H$, et al. Specific sites of metastases in invasive lobular carcinoma: a retrospective cohort study of metastatic breast cancer. Breast Cancer. 2017;24(5):667-72

13. Ferry A, Font R. Carcinoma metastatic to the eye and orbit I. a clinicopathologic study of 227 cases. Arch Ophthalmol. 1974:92(4):276-86.

14. Wladis EJ, Lee KW, Nazeer T. Metastases of systemic malignancies to the orbit: a major review [published online ahead of print, 2020 Apr 27]. Orbit 2020:1-5.

15. Georgalas I, Paraskevopoulos T, Koutsandrea C, Kardara E, Malamos P, Ladas $D$, et al. Ophthalmic metastasis of breast cancer and ocular side effects from breast cancer treatment and management: mini review. Biomed Res Int. 2015;2015:574086

16. Homer N, Jakobiec FA, Stagner A, Cunnane ME, Freitag SK, Fay A, et al. Periocular breast carcinoma metastases: correlation of clinical, radiologic and histopathologic features. Clin Exp Ophthalmol. 2017;45(6):606-12.

17. Tsagkaraki IM, Kourouniotis CD, Gomatou GL, Syrigos NK, Kotteas EA. Orbital metastases of invasive lobular breast carcinoma. Breast Dis. 2019:1:1-7.

18. Raap M, Antonopoulos W, Dämmrich M, Christgen H, Steinmann D, Länger $F$, et al. High frequency of lobular breast cancer in distant metastases to the orbit. Cancer Med. 2014;4(1):104-11.

19. Nifosí G, Zuccarello M. Unilateral localized extraocular muscle metastasis by lobular breast carcinoma. BMJ Case Rep. 2018;2018:bcr-2018-224726.

20. Jakobiec FA, Stagner AM, Homer N, Yoon MK. Periocular breast carcinoma metastases: predominant origin from the lobular variant. Ophthalmic Plast Reconstr Surg. 2017;33(5):361-6.

21. Text Information Extraction System (TIES) Software. Available from: http:// www.ties.dbmi.pitt.edu/. Accessed 6 Jan 2020.

22. Jacobson RS, Becich MJ, Bollag RJ, Chavan G, Corrigan J, Dhir R, et al. A federated network for translational cancer research using clinical data and biospecimens. Cancer Res. 2015;75(24):5194-201.

23. Vector realistic human eye cross section side view close up isolated on white baclground [sic]. Available from: https://www.shutterstock.com/ image-vector/vector-realistic-human-eye-cross-section-1298160145. Accessed 6 Jan 2020.

24. Maheshwari A, Finger PT. Cancers of the eye. Cancer Metastasis. 2018;37(2): $1-14$.

25. Shields JA, Shields CL, Brotman HK, Carvalho C, Perez N, Eagle RC. Cancer metastatic to the orbit. Ophthalmic Plast Reconstr Surg. 2001;17(5):346-54

26. Parrozzani R, Frizziero L, Testi I, Miglionico G, Perrini P, Pulze S, et al. Intraocular metastases secondary to breast carcinoma correlates with upregulation of estrogen and progesterone receptor expression in the primary tumor. Invest Ophthalmol Vis Sci. 2016;57:3944-8.

27. Sindoni A, Fama' F, Vinciguerra P, Dionigi G, Manara S, Gioffre'-Florio M, et al. Orbital metastases from breast cancer: A single institution case series [published online ahead of print, 2020 Apr 15]. J Surg Oncol 2020;10.1002.

28. Nowikiewicz T, Wiśniewska M, Wiśniewski M, Biedka M, Głowacka I, Kozak D, et al. Overall survival and disease-free survival in breast cancer patients treated at the Oncology Centre in Bydgoszcz - analysis of more than six years of follow-up. Contemp Oncol (Pozn). 2015;19(4):284-9.

29. van Nispen RM, de Boer MR, Hoeijmakers JG, Ringens PJ, van Rens GH. Comorbidity and visual acuity are risk factors for health-related quality of life decline: five-month follow-up EQ-5D data of visually impaired older patients. Health Qual Life Outcomes. 2009;7:18.

30. Framarino-Dei-Malatesta M, Chiarito A, Bianciardi F, Fiorelli M, Ligato A, Naso $G$, et al. Metastases to extraocular muscles from breast cancer: case report and up-to-date review of the literature. BMC Cancer. 2019;19:36.

31. Wiegel T, Kreusel KM, Bornfeld N, Bottke D, Stange M, Foerster MH, et al. Frequency of asymptomatic choroidal metastasis in patients with disseminated breast cancer: results of a prospective screening programme. Br J Ophthalmol. 1998;82(10):1159-61. 
32. Ogueta SB, Schwartz SD, Yamashita CK, Farber DB. Estrogen receptor in the human eye: influence of gender and age on gene expression. Invest Ophthalmol Vis Sci. 1999;40(9):1906-11.

33. Colitz CM, Lu P, Sugimoto Y, Barden CA, Chandler HL. Estradiol biosynthesis in canine lens epithelial cells. Curr Eye Res. 2015;40(5):541-8.

\section{Publisher's Note}

Springer Nature remains neutral with regard to jurisdictional claims in published maps and institutional affiliations.

Ready to submit your research? Choose BMC and benefit from:

- fast, convenient online submission

- thorough peer review by experienced researchers in your field

- rapid publication on acceptance

- support for research data, including large and complex data types

- gold Open Access which fosters wider collaboration and increased citations

- maximum visibility for your research: over $100 \mathrm{M}$ website views per year

At $B M C$, research is always in progress.

Learn more biomedcentral.com/submissions 